\title{
Odong-Odong Apoteker: Maskot Baru untuk Sosialisasi GEMACERMAT
}

Andy Eko Wibowo*, Rifki Febriansyah, Ingenida Hadning, Pinasti Utami, Aji Winanta

Fakultas Kedokteran dan Ilmu Kesehatan, Prodi Farmasi, Universitas Muhammadiyah Yogyakarta, Jln. Brawijaya, Kasihan, Bantul, Yogyakarta 55183, Indonesia

$$
\text { *andyew@umy.ac.id }
$$

Submisi: 05 September 2018; Penerimaan: 25 November 2019

Kata Kunci:.
apoteker;
GEMACERMAT;
IYPG;
IAI;
odong-odong.

Keywords: GEMACERMAT; $I Y P G$;

IAI; odong-odong; Pharmacist.
Abstrak Odong-Odong Apoteker, Simbol, dan Media Branding Eksistensi Apoteker di Masyarakat Indonesia dalam Rangka Gerakan Masyarakat Cerdas Sadar Obat (GEMACERMAT) adalah gerakan yang dilandasi oleh keterpurukan image apoteker dua tahun terakhir akibat berbagai kasus yang terjadi di Indonesia. Tujuan odongodong apoteker adalah menjadi simbol eksistensi dan peran apoteker di masyarakat. Metode yang digunakan adalah pembuatan odong-odong berbentuk apoteker memegang kapsul; mengubah lirik lagu anak-anak menjadi lirik seputar pengetahuan dasar obat yang harus diketahui masyarakat; dan memperkenalkan odong-odong sebagai maskot baru apoteker anggota IAI Cabang Bantul dan apoteker anggota IYPG Cabang Yogyakarta ketika penyelenggaraan kegiatan pengabdian masyarakat. Hasil pengabdian ini adalah odong-odong apoteker tercipta dengan berbagai lagu anak-anak yang telah diubah liriknya. Odong-odong apoteker pertama kali digunakan oleh IAI ketika melakukan penyuluhan obat antibiotik pada acara jalan sehat dalam rangka Hari Kemerdekaan Republik Indonesia ke-73 yang diselenggarakan oleh Karang Taruna Tanuditan Bantul. Odong-odong apoteker telah diletakkan di beberapa apotek milik apoteker anggota IYPG. Odong-odong apoteker menjadi tempat yang disukai anak-anak untuk bermain sekaligus menikmati lagulagu yang berisi pengetahuan seputar obat-obatan. Lagu-lagu tersebut diharapkan dapat masuk ke alam bawah sadar masyarakat dan secara tidak langsung mengedukasi mereka perihal penggunaan obat.

Abstract Pharmacist Odong-Odong, Symbols, and Media Branding the Pharmacist's Existence in Indonesian Communities within the framework of the Drug Conscious Smart Society Movement (GEMACERMAT) is a movement based on the deterioration of the pharmacist's image in the last two years due to various cases in Indonesia. The goals of pharmacists odong-odong become symbols of the existence and role of pharmacists in society. The method used is making odongodong in the form of a pharmacist holding a capsule, turning children's song lyrics into lyrics about basic knowledge of medicine that the public must know and introducing odong-odong as the new mascot of the pharmacists of IAI Bantul Branch members and pharmacists of IYPG members of the Yogyakarta Branch when they organizing community service activities. The result of this community service is that pharmacists odong-odong are created with various children's songs whose lyrics have been changed. The pharmacist odong-odong, was first used by the IAI when conducting antibiotic drug counseling at a healthy walk event in the framework of the 73rd Independence Day of the Republic of Indonesia organized by Karang Taruna Tanuditan Bantul. Odong-odong pharmacists have also been placed in several pharmacies belonging to IYPG member pharmacists. Pharmacists odongodong become a favorite place for children to play while enjoying a song that contains knowledge about medicine. The songs are expected to enter the subconscious of the community and indirectly educate the use of drugs. 


\section{PENDAHULUAN}

"Suami saya meninggal didiagnosa gagal jantung. Waktu keluar surat kematian dari lurah, dituliskan penyebab kematiannya karena sudah lanjut usia. Mereka tidak tahu kalau lima minggu sebelum meninggal, suami saya mengalami sesak napas,keringat dingin, dan kesadarannya berangsur hilang. Selama lima minggu berjuang, suami saya diberikan lima antibiotik untuk mengatasi infeksinya. Yang pertama gagal, kedua gagal, ketiga gagal, keempat gagal, saat kelima, jantung, paru-paru, ginjalnya sudah tidak kuat. Kegagalan tersebut disebabkan oleh resistensi antibiotika" tutur Nafsiah Mboi, Mantan Menteri Kesehatan Republik Indonesia (Disideria, 2015).

Kasus di atas adalah salah satu contoh dari tujuh ribu kasus kematian yang disebabkan oleh resistensi antibiotik yang terjadi di dunia pada 2014. WHO memperkirakan bahwa kematian akibat resistensi antimikroba dapat mencapai 10 juta jiwa per tahun pada 2050 (Kemenkes RI, 2016). Oleh karena itu, tindak lanjut untuk mengatasi masalah ini perlu segera dilakukan oleh semua pihak. Menanggapi terjadinya kasus resistensi antibiotik tersebut, Kemenkes Republik Indonesia menggaungkan slogan GEMACERMAT (Gerakan Masyarakat Cerdas Gunakan Obat).

GEMACERMAT dicanangkan berdasarkan Surat Keputusan Menteri Kesehatan RI Nomor HK 02.02/MENKES/427/2015. Berbagai kegiatan untuk meningkatkan penggunaan obat secara tepat dan benar kepada masyarakat digalakkan melalui gerakan tersebut, antara lain mencegah peredaran antibiotik secara bebas di apotek dengan penandatanganan pakta integritas bagi para apoteker; mengampanyekan penggunaan antibiotik yang tepat kepada masyarakat; dan membentuk tim Agent of Change (AoC) GEMACERMAT. Meskipun demikian, semua branding yang telah dibuat oleh pemerintah tentang GEMACERMAT belum memiliki simbol yang dapat digunakan untuk menyebarluaskan gerakan tersebut ke masyarakat. 
Di sisi lain, pamor keprofesian apoteker meredup pada dua tahun ini karena berbagai kasus yang terjadi, yakni mulai dari peredaran vaksin palsu pada 2016 (Maysia et al., 2016), kasus obat PCC palsu (Suri, 2017; Anugerah, 2017), dan kasus penjualan bebas tramadol dan somadril (Hadron, 2014). Kasus-Kasus tersebut membuat gelar profesi apoteker diragukan peran dan fungsinya, baik di mata masyarakat maupun di mata profesi lainnya, seperti dokter. Para apoteker anggota Ikatan Apoteker Indonesia Wilayah Bantul (PC IAI Bantul) dan para apoteker anggota Indonesian Young Pharmacist Group (IYPG Yogyakarta) merupakan dua kelompok yang ingin menepis dan menjawab tantangan akan meredupnya pamor keprofesian apoteker tersebut. Hal itu disebabkan kepercayaan masyarakat dan berbagai pihak lainnya adalah modal terpenting dalam menjalankan pekerjaan keprofesian dan untuk menunjang tercapainya tujuan utama, yakni terciptanya kesehatan seluruh masyarakat Indonesia.

Odong-odong apoteker adalah salah satu usaha yang bisa digunakan oleh para apoteker, baik PC IAI Bantul maupun IYPG Yogyakarta, untuk menanamkan peran sertanya sebagai konsultan obat di benak masyarakat dan tenaga kesehatan lainnya. Odong-odong apoteker juga digunakan sebagai sarana sosialisasi Gerakan Masyarakat Cerdas Menggunakan Obat (GEMACERMAT). Dengan odong-odong apoteker ini, para apoteker dari kedua kelompok tersebut akan memiliki simbol untuk meningkatkan pamor keprofesian mereka.

Berikut ini adalah lima alasan odong-odong apoteker dianggap mampu menjadi simbol yang akan menyukseskan program GEMACERMAT dan meningkatkan pamor para apoteker.

(a) Odong-odong adalah mainan anak-anak yang biasanya diletakkan di swalayan atau apotek serta di tempat orang banyak berkumpul. Dengan penampilan apoteker dalam bentuk odong-odong, orang akan bertanya-tanya mengapa odong-odong 
tersebut memiliki bentuk yang lucu sehingga diharapkan akan memunculkan rasa penasaran tentang profesi apoteker.

(b) Saat anak ingin bermain dengan odong-odong, orang tua akan selalu berada di sekitar odong-odong. Ketika odong-odong yang berbentuk apoteker bergerak, musik dari Gerakan Masyarakat Cerdas Penggunaan Obat (GEMACERMAT) yang mengiringi lagu-lagu dengan lirik tentang kesadaran penggunaan obat akan terdengar. Lagu-lagu tersebut dinyanyikan oleh anak-anak dan ditujukan kepada orang tua. Hal tersebut diharapkan akan membuat alam bawah sadar para orang tua memahami perihal penggunaan obat, terutama antibiotik yang benar dan baik untuk anaknya, dirinya, dan orang lain. Secara tidak langsung, orang tua menjadi Agent of Change (AoC) GEMACERMAT.

(c) Musik yang mengiringi lagu-lagu yang lirik-liriknya tentang kesadaran penggunaan obat juga akan terdengar oleh orang-orang yang ada di sekitar odong-odong yang diputar. Apabila lagu-lagu tersebut terus terdengar, orang-orang di sekitar odongodong juga diharapkan akan memahami perihal penggunaan obat-obatan dengan baik dan benar.

\section{METODE PELAKSANAAN}

Cara/metode dalam implementasi perlu dipilih untuk mencapai tujuan program ini. Metode yang diterapkan adalah pembuatan odong-odong; penggubahan lirik lagu anak anak menjadi lirik tentang pengetahuan obat; dan penggunaan odong-odong dalam acara penyuluhan/pengabdian yang diselenggarakan oleh para apoteker anggota Ikatan Apoteker Indonesia Cabang Bantul dan para apoteker anggota Indonesia Young Pharmacist Group Cabang Yogyakarta. Pembuatan odong-odong dilakukan dengan mendesain patung apoteker terlebih dahulu, membuat cetakan, mencetak dengan menggunakan fiber, dan melakukan pengecatan. 
Adapun pembuatan lagu dilakukan dengan menggubah berbagai lirik lagu anakanak menjadi lirik lagu yang berkaitan dengan pengetahuan obat-obatan. Lagu tersebut kemudian diperkenalkan ke salah satu sekolah taman kanak-kanak untuk selanjutnya direkam. Odong-odong yang sudah jadi dan dilengkapi dengan berbagai musik dan lagu dengan lirik yang berkaitan dengan pengetahuan obat-obatan digunakan sebagai simbol pengabdian para apoteker anggota Ikatan Apoteker Indonesia Cabang Bantul dan para anggota Indonesia Young Pharmacist Group Cabang Yogyakarta.

\section{HASIL DAN PEMBAHASAN}

\subsection{Pembuatan Odong-Odong}

Pembuatan bekerja sama dengan pematung 'Solo Toys Center'. Proses pembuatan odong-odong melalui beberapa tahap (Gambar 1). Hal pertama yang dilakukan adalah membuat karakter apoteker melalui software autocad. Karakter manusia dipilih daripada kartun agar citra apoteker yang sesungguhnya lebih dipandang dan dikenal. Oleh karena itu, langkah selanjutnya adalah pembuatan cetakan berbentuk patung apoteker (Gambar 2). Cetakan tersebut lalu digunakan untuk membuat karakter apoteker dengan menggunakan fiber. Rangka odong-odong juga dibuat secara bersamaan. Tahap terakhir adalah pengecatan dan pemasangan karakter odong-odong seperti yang terlihat pada (Gambar 3).

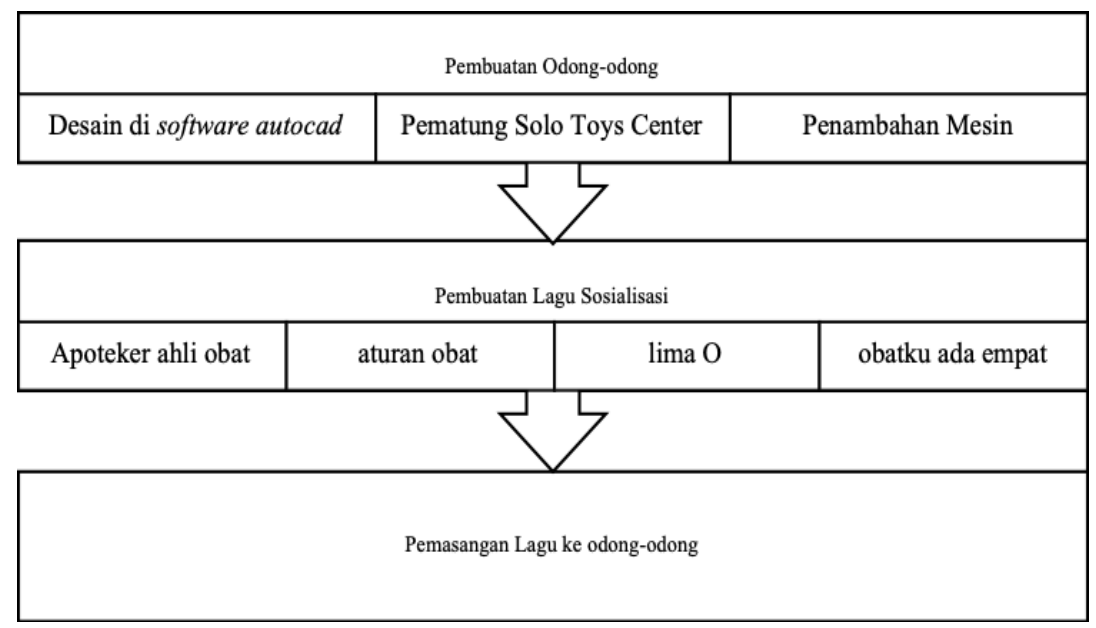

Sumber: Data Primer Diolah (2018) 
Gambar 1. Proses Pembuatan Odong-Odong

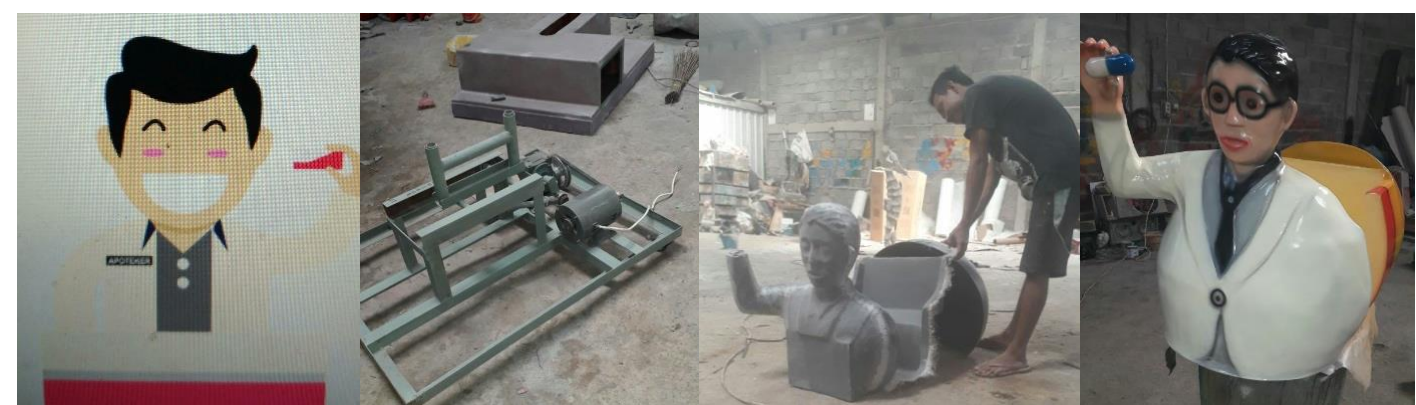

Sumber: Data Primer Diolah (2018)

Gambar 2. Tahap Pembuatan Odong-Odong Apoteker

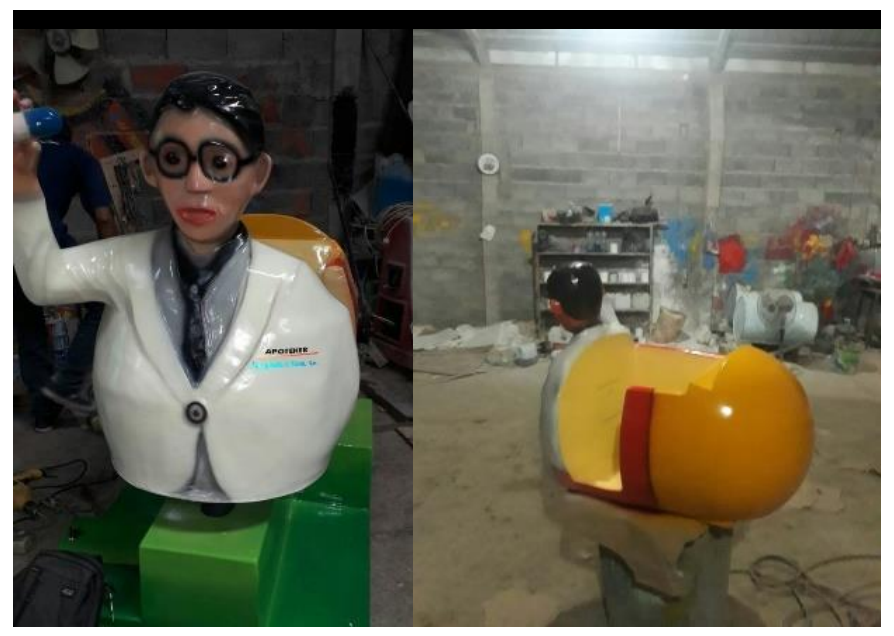

Sumber: Data Primer Diolah (2018)

Gambar 3. Odong-Odong dengan Karakter Apoteker dan Tempat Duduk Kapsul

\subsection{Penggubahan Lirik Lagu Anak-Anak}

Lirik lagu anak-anak yang digubah menjadi lirik lagu edukasi tentang obat-obatan, antara lain lagu "Balonku Ada Lima" menjadi "Obatku Ada Empat”, "Burung Kakak Tua” menjadi “Apoteker Ahli Obat”, “Topi Saya Bundar” menjadi "Cara Minum Obat”, "Pelangi-Pelangi" menjadi "Apoteker Tercinta", dan "Potong Bebek Angsa" menjadi “Tanya Aturan Obat pada Apoteker". Lirik lagu tersebut ditulis dalam notasi angka. Berikut salah satu contoh notasi angka yang digunakan sebagai panduan menyanyi (Gambar 4). 


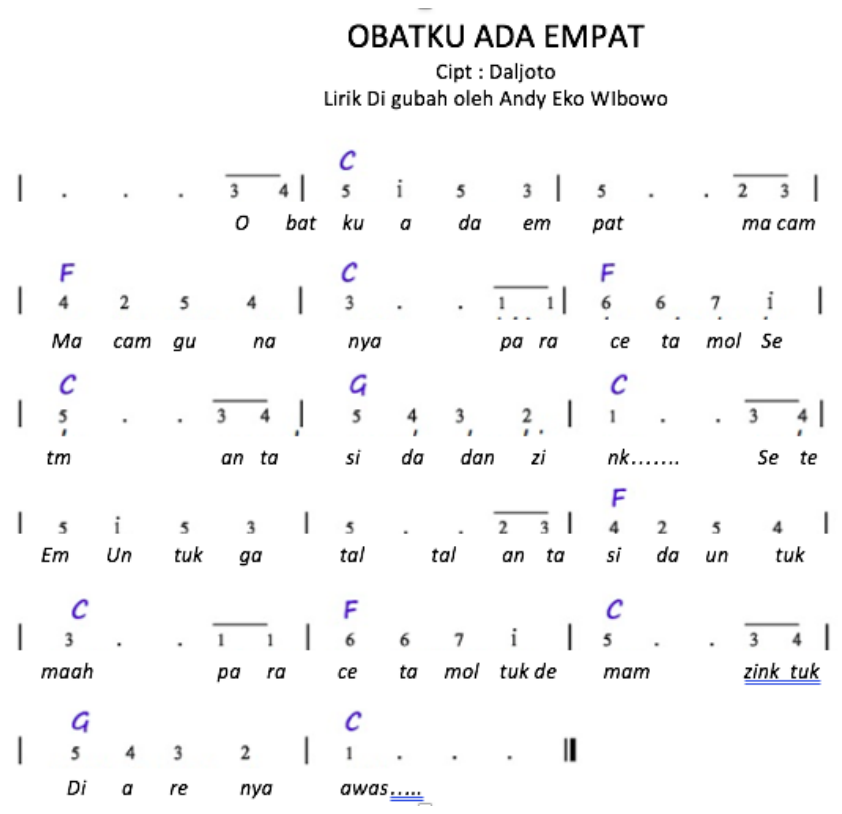

Reff:

Gunakan dengan benar...

Tanyakan apoteker....

Badan sehat dan kuat

Pilih obat yang tepat...

Sumber: Data Primer Diolah (2018)

Gambar 4. Salah Satu Contoh Gubahan Lirik Lagu "Balonku Ada Lima” Menjadi

“Obatku Ada Empat”

Beberapa lagu yang telah digubah liriknya dan dilengkapi dengan notasi angka kemudian diserahkan kepada salah satu guru di taman kanak-kanak yang telah ditentukan. Lagu tersebut kemudian dipelajari dan dinyanyikan oleh murid-murid tersebut. Adapun langkah terakhir adalah perekaman.

\subsection{Implementasi Odong-Odong Apoteker sebagai Maskot Penyuluhan}

Apresiasi yang tinggi terhadap maskot odong-odong apoteker oleh para apoteker anggota Ikatan Apoteker Indonesia Cabang Bantul dibuktikan dengan adanya beberapa permintaan untuk menghadirkan odong-odong apoteker di tempat-tempat kegiatan pengabdian atau tempat praktik para anggota (Gambar 5). Kegiatan pengabdian pertama yang dilakukan adalah penyuluhan tentang obat serta cek kesehatan pada saat acara 
jalan sehat yang diselenggarakan oleh Karang Taruna Tanuditan Bantul dalam rangka

Hari Kemerdekaan Republik Indonesia ke-73. Kegiatan diawali dengan jalan sehat kemudian dilanjutkan dengan cek kesehatan (tensi, kolesterol, asam urat, gula darah), penyuluhan oleh para apoteker tentang obat-obat antibiotik, serta doorprice. Odongodong apoteker yang berada di tempat kegiatan menarik perhatian anak-anak. Mereka pun secara spontan meminta kepada orang tuanya untuk menaiki odong-odong apoteker tersebut.

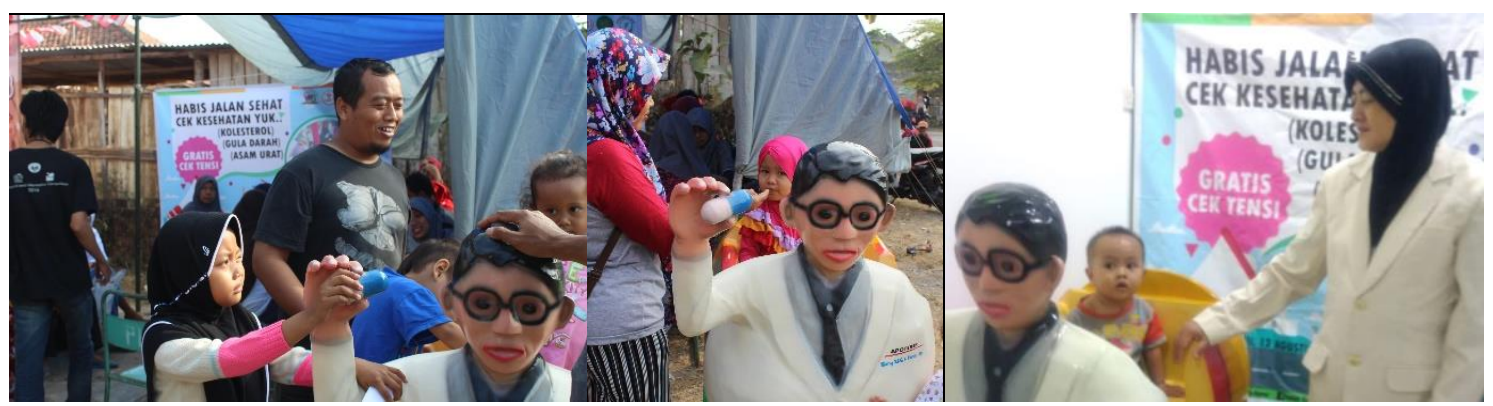

Sumber: Data Primer Diolah (2018)

Gambar 5. Odong-Odong Apoteker Diminati Anak-Anak

Kegiatan pengabdian tersebut mendapat respons yang tinggi dari peserta jalan sehat karena mereka mendapatkan pengetahuan baru mengenai tata cara penggunaan obatobatan degenaratif, seperti obat asam urat, obat kolesterol, obat gula darah, serta obat antibiotik, baik melalui penyuluhan maupun lagu-lagu yang berasal dari odong-odong apoteker. Beberapa bentuk respons langsung yang diberikan oleh peserta jalan sehat adalah usulan agar karakter odong-odong dibuat lebih lucu sehingga anak-anak lebih tertarik dan memperbanyak lagu-lagu di odong-odong apoteker tersebut.

Odong-odong apoteker juga ditempatkan secara bergilir di apotek milik para apoteker anggota Indonesia Young Pharmacist Group Cabang Yogyakarta (Gambar 6). Dengan adanya odong-odong tersebut, pasien yang datang ke apotek diharapkan akan mendapatkan pengetahuan mengenai obat-obatan melalui lagu-lagu yang didengarkan pada saat anak-anak menaiki odong-odong tersebut. Odong-odong apoteker juga berdampak secara ekonomi bagi para apoteker anggota IYPG, yakni melalui penjualan 
koin odong-odong. Penempatan odong-odong apoteker selanjutnya akan digilir secara periodik ke masing-masing apoteker anggota IYPG. Kendala yang dihadapi adalah jumlah odong-odong apoteker yang terbatas sehingga tidak bisa mengedukasi masyarakat secara serentak.

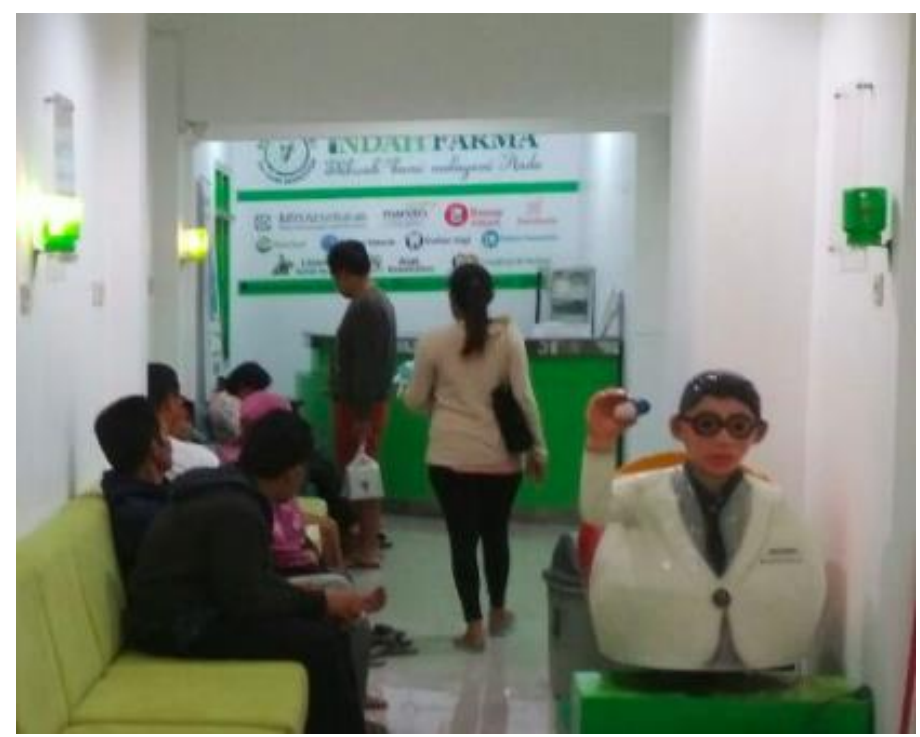

Sumber: Data Primer Diolah (2018)

Gambar 6. Odong-Odong Apoteker di Salah Satu Apotek Milik Apoteker Anggota Indonesia Young Pharmacist Group Cabang Yogyakarta

\section{KESIMPULAN}

Odong-odong apoteker sebagai media branding para apoteker Anggota Ikatan Apoteker Indonesia Cabang Bantul dan apoteker anggota Indonesia Young Pharmacist Group Cabang Yogyakarta telah berhasil direalisasikan menjadi maskot baru Gerakan Masyarakat Cerdas Menggunakan Obat (GEMACERMAT).

Odong-odong apoteker memiliki lagu anak-anak dengan lirik tentang pengetahuan obat obatan, memberikan dampak secara tidak langsung kepada orang yang mendengar lagu tersebut dapat mengenal obat-obatan seperti aturan obat serta bilat tidak tahu informasi obat harus bertanya kepada apoteker, serta penggunaan antibiotika yang harus sesuai aturan. 
Odong-odong apoteker ini dapat digunakan sebagai maskot pada saat kegiatan penyuluhan, maupun diletakkan di apotek untuk mengedukasi langsung pasien melalui lagunya serta berdampak ekonomi pada apotek yang ditempati.

\section{UCAPAN TERIMAKASIH}

Lembaga Penelitian Pengembangan dan Pengabdian kepada Masyarakat (LP3M) Universitas Muhammadiyah Yogyakarta atas Program Hibah Program Kemitraan Masyarakat Tahun Anggaran 2017-2018; Ikatan Apoteker Indonesia Cabang Bantul sebagai mitra dalam program Kemitraan Masyarakat untuk odong-odong apoteker; Indonesia Young Pharmacist Group Cabang Yogyakarta sebagai mitra dalam program kemitraan masyarakat untuk peletakkan odong-odong apoteker di tempat praktek; Karang Taruna Tanuditan dalam kegiatan jalan sehat dalam rangka kemerdekaan RI ke73 atas kesempatan untuk mengabdi di tempat tersebut.

\section{DAFTAR PUSTAKA}

Arbi Anugerah. (2017). BPOM Mengaku Bersalah atas peredaran Vaksin Palsu, BBC Indonesia, Jakarta.

Disideria, Benecdikta. (2015). Penyebab Meninggalnya Suami Nafsiah Mboi. Diakses pada 4 September 2018, diambil dari Liputan6.com, https://www.liputan6.com/health/read/2287554/ini-penyebab-meninggalnyasuami-nafsiah-mboi.

Hadron, Anita P. (2014). Somadril and Edgework in South Sulawesi, International. Journal of Drug Policy, Science Direct, 25(4): 755-761.

Kemenkes RI. (2016). Mari Bersama Atasi Resistensi Antimikroba (AMR). Diakses pada $\quad 4 \quad$ September 2018, diambil dari 
www.depkes.go.id/article/print/16060800002/mari-bersama-atasi-resistensi-

antimikroba-amr-.html

Maysia, Inas, I Nyoman Musiasa, \& Mohammad Shihab. (2016). Komunikasi Pasca Krisi Vaksin Palsu di RS Karya Medika II Tambun- Sebuah Studi Pendahuluan. Prosiding Magister Ilmu Komunikasi, Universitas Negeri Lampung, Indonesia.

Surat Keputusan Menteri Kesehatan Republik Indonesia tentang Gerakan Masyarakat Cerdas Penggunaan Obat nomor HK 02.02/MENKES/427/2015, Kementerian Kesehatan Republik Indonesia, Jakarta.

Suri, Nurma. (2017). Sejarah Singkat Obat Racikan Psikotropika Murah Meriah bernama Karisoprodol. Jurnal Universitas Padjajaran. Indonesia 